\title{
Política de cotas da UNEB: ação institucional com ressonância nacional
}

\author{
Ana Paula Souza do Prado Anjos ${ }^{1}$ \\ Marilde Queiroz Guedes²
}

\section{Resumo}

Em uma sociedade de privilégios, criar políticas de cotas raciais para democratização da educação superior representa uma audácia. Com o objetivo de analisar as contribuições da política de cotas para democratização de acesso à educação superior criada pela Universidade do Estado da Bahia (UNEB), enquanto uma ação institucional, foi realizada uma pesquisa de caráter documental e bibliográfica. Os resultados revelam que a política de cotas raciais e sociais criada pela UNEB, para acesso à graduação e a pós-graduação, foi uma ação institucional pioneira, que teve repercussão nacional.

\section{Palavras-chaves}

Cotas; políticas públicas; educação superior.

\section{Politics UNEB quotas: institutional action with national resonance}

\begin{abstract}
In a society of privileges, creating racial quota policies to democratize higher education is audacious. In order to analyze the contributions of the quota policy to democratize access to higher education created by the University of the State of Bahia (UNEB), as an institutional action, a documentary and bibliographic research was carried out. The results reveal that the racial and social quotas policy created by UNEB, for access to undergraduate and graduate courses, was a pioneering institutional action, which had national repercussions.
\end{abstract}

Keywords

Quotas; public policy; college education.

Artigo recebido: novembro de 2020

Artigo aprovado: dezembro de 2020 


\section{Introdução}

Ao considerar que as desigualdades sociais, econômicas, culturais e educacionais impulsionam a criação de políticas públicas em diferentes instituições e esferas do poder, defendemos que é preciso educar o olhar (atenção institucional) para percebê-las como problemas que atingem a dignidade humana, principalmente, das minorias subalternizadas na sociedade. Nessa perspectiva, o objeto de análise desse artigo - sistema de cotas implementado pela UNEB para acesso de segmentos minoritários à educação superior - tem como pretensão demonstrar as possibilidades de desenvolvimento de políticas públicas para minimizar os problemas locais, a partir de medidas institucionais.

A universidade é uma instituição social (CHAUÍ, 2003), "que se realiza por meio de práticas humanas e sociais, portanto, ações constitutivas do ético e do político" (DIAS SOBRINHO, 2005, p. 31). Enquanto tal, a universidade também tem se constituído em lócus de realização de políticas públicas, com vistas a atender as necessidades urgentes da vida humana. No contexto dessa abordagem está a Universidade do Estado da Bahia (UNEB), uma instituição multicampi, que congrega 29 departamentos distribuídos em 24 campus, atendendo à demanda educacional dos 19 territórios de identidade do Estado da Bahia, localizada na região Nordeste do Brasil. É a maior universidade multicampi do Brasil e está entre as 80 melhores universidades da América Latina, de acordo com o Ranking Universitário Latino-Americano, promovido pela revista Times Higher Education (AGÊNCIA INOVAÇÃO, 2017).

A estrutura multicampi adotada pela UNEB possibilitou a implantação de novos cursos e campi universitários em regiões com baixos indicadores sociais, que demandavam políticas governamentais pautadas em ações de caráter educativo. "Segundo Boaventura (2009, p. 662), a UNEB nasceu com a cor da Bahia, comprometida com suas regiões, com a negritude, com os sertões, com a pobreza, com os problemas de educação, de alimentação e de saúde". 
O engajamento social da instituição tem possibilitado um contato maior com a sociedade e conhecimento dos problemas que a atinge. Esse olhar atento e as reivindicações dos coletivos organizados foram essenciais para que a gestão e a comunidade acadêmica da instituição percebessem que era preciso fazer algo mais para democratizar o ingresso de determinados grupos étnicos na universidade, visto que, com maior qualificação profissional e acesso a conhecimentos, os mesmos poderiam se empoderar, melhorar as próprias condições socioeconômicas e promover transformações no contexto em que estavam inseridos.

Enquanto servidora da instituição, na função de Assessora Pedagógica de um campus do interior do estado e pesquisadora dessa política, sob algumas perspectivas ${ }^{3}$, proponho neste texto analisar a implementação, desenvolvimento e efetividade da política de cotas citada, a partir de dados dos anuários e relatórios publicados pela UNEB, além de produções teóricas sobre ações afırmativas.

Para melhor sistematização, o objeto da pesquisa foi analisado a partir de todas as etapas que constituem o ciclo de políticas públicas (identificação do problema, formação de agenda, formulação de alternativas, tomada de decisão, implementação, avaliação e extinção), à luz das teorias defendidas por Wu et al (2014) e Souza (2018), com contribuições de outros referenciais. Os dados apresentados destacam as ações desenvolvidas, os avanços e os desafios para consolidação da política de cotas no âmbito da instituição.

\section{Dimensões epistemológicas das políticas públicas}

O Brasil é um país de dimensão continental, que em 2019 tinha uma população estimada pelo Instituto Brasileiro de Geografia e Estatística - IBCE em 210.147.125 habitantes. Economicamente, teve crescimento médio de 1,39\% na última década segundo dados do Instituto de Pesquisa Econômica Aplicada (2019), classificado na 79a posição do ranking do Índice de Desenvolvimento Humano (IDH), considerada a 
segunda nação com maior concentração de renda do mundo, no qual $1 \%$ dos mais ricos concentra $28,3 \%$ dos rendimentos do país de acordo com a Organização das Nações Unidas (2019). Os dados apresentados revelam crise na economia brasileira e desigualdades significativas nos indicadores sociais e de renda. Diante desse panorama, que não se restringe às últimas décadas, mas é resultado de, aproximadamente, três séculos de colonização (1.500 a 1.822) e intensificação do capitalismo neoliberal, as políticas públicas configuram como mecanismos necessários para minimização das desigualdades.

Registra-se, de pronto, que nesse trabalho a concepção de políticas públicas é de forma abrangente, não a reduzindo a ações destinadas à diminuição da pobreza, mas a todas as responsabilidades do Estado na garantia de vida digna a todos os habitantes, seja nas áreas de educação, saúde, saneamento, segurança, habitação, cultura, desenvolvimento regional, reconhecimento social das minorias étnico-raciais e sociais, dentre outras. Embora saibamos da existência do Estado mínimo, as demandas sociais asseguradas constitucionalmente continuam de responsabilidade do Estado, mesmo ele fazendo a política da desobrigatoriedade.

Como uma área de estudo recente, que surge a partir dos conflitos entre capital e trabalho no século XIX, a definição de política pública ainda está em processo de construção, devido sua amplitude de atuação. Em uma síntese, elaborada por Souza, percebemos que,

Mead (1995) a define como um campo dentro do estudo da política que analisa o governo à luz de grandes questões públicas. Lynn (1980) a define como um conjunto específico de ações do governo que irão produzir efeitos específicos. Peters (1986) segue o mesmo veio: política pública é a soma das atividades dos governos, agindo diretamente ou através de delegação, que influenciam a vida dos cidadãos. Dye (1984: 13) sintetiza a definição de política pública como "o que o governo escolhe fazer ou não fazer” (SOUZA, 2018, p. 13). 
Essas definições evidenciam o papel do Estado na criação e desenvolvimento das políticas públicas. No entanto, a deliberação de quais políticas serão criadas e as áreas a serem beneficiadas são movidas pelo embate e pressão dos cidadãos, dos movimentos sociais, grupos políticos e econômicos. É um processo conflituoso e de poder, para inserção de determinadas pautas na agenda formal do governo, especialmente, quando se trata da melhoria das condições de vida dos sujeitos, que as tem tão precarizadas. Por isso, Fraser (2007) salienta a importância da representação democrática das minorias nos espaços políticos e de poder, para inserir suas pautas de reivindicações na agenda formal e política do governo ou do Estado, e persuadir os pares para aprovações de projetos e leis, que viabilizem melhor redistribuição de riquezas e reconhecimento social, por meio de políticas públicas.

Como as ações do Estado são organizadas por áreas de abrangência, na educação, as políticas públicas "dizem respeito às decisões do governo que têm incidência no sistema escolar enquanto ambiente de ensino-aprendizagem" (OLIVEIRA, 2010, p. 5). No sistema educacional pode-se situar outras políticas públicas de abrangência mais específicas, como as de ações afırmativas (discriminação positiva), que têm por objetivo "eliminar desigualdades historicamente acumuladas, garantindo a igualdade de oportunidades e tratamento, bem como compensar perdas provocadas pela discriminação e marginalização decorrentes de motivos raciais, étnicos, religiosos, de gênero e outros" (SANTOS, 1999, p. 25).

Nesse sentido, os estudantes do ensino superior foram contemplados no Plano Nacional de Educação - PNE 2014-2024, Meta 12, que propõe a elevação da taxa bruta de matrícula para cinquenta por cento, especificando na Estratégia 12.5

Ampliar as políticas de inclusão e de assistência estudantil dirigidas aos(às) estudantes de instituições públicas, bolsistas de instituições privadas de educação superior e beneficiários do Fundo de Financiamento Estudantil (FIES), de que trata a Lei $n^{\circ}$ 
10.260, de 12 de julho de 2001, na educação superior, de modo a reduzir as desigualdades étnico-raciais e ampliar as taxas de acesso e permanência na educação superior de estudantes egressos da escola pública, afrodescendentes e indígenas e de estudantes com deficiência, transtornos globais do desenvolvimento e altas habilidades ou superdotação, de forma a apoiar seu sucesso acadêmico (BRASIL, 2014, p. 207).

O sistema de cotas para ingresso nos cursos de graduação e pós- graduação da UNEB situa-se como uma política pública de ação afırmativa institucional para democratização do ensino superior. O sistema de cotas implantado na instituição configura como uma política botton-up "de baixo, ou do local, para cima" (SOUZA, 2018, p. 27), ou seja, foi criada por uma instituição que tem autonomia didático-científıca, administrativa e de gestão financeira, a partir das reivindicações dos movimentos negros e sociais e da própria comunidade acadêmica.

Apesar da instituição fazer parte da administração pública, o sistema de cotas não configura uma política de Estado, porque essa tem uma abrangência maior, caráter contínuo e depende da aprovação de várias instâncias político-administrativas, assim como, não pode ser classificada como política pública governamental, por não ter sido criada pela vontade ou plano de um governo específico, em determinado momento da história.

\section{Sistemas de cotas da UNEB: uma política pública para democratização de acesso à educação superior}

A política de cotas implementadas pela UNEB, no âmbito da educação superior, foi criada no ano 2000 , em um contexto de intensa desigualdade social e restrito acesso de determinados grupos étnicos à universidade, bem como a outros direitos fundamentais, assegurados constitucionalmente. A Bahia, considerada o quinto maior estado do Brasil em dimensão territorial, o quarto em quantidade de habitantes e com uma população 13\% autodeclarada negra e 0,5\% indígena, 
nesse mesmo ano, apresentou uma taxa de analfabetismo de 21,5\% (negros) e 8,3\% (brancos) na população com 15 anos ou mais. Já o quantitativo de adultos graduados era muito baixo, restringia-se a: pardos $(2,4 \%)$, indígenas $(2,2 \%)$, pretos $(2,1 \%)$, brancos $(9,9 \%)$, conforme dados do IBCE (2000). Embora a dificuldade de acesso à educação superior constituísse um problema nacional, atingindo principalmente a população afrodescendente, na Bahia, atingia a população em maior dimensão porque era um dos estados com o quantitativo de negros e pardos (74\%), segundo dados do (IBCE, 2000).

Somado a esse panorama, no início do século XXI houve uma intensificação das reivindicações do movimento negro, pelo direito à educação e à inclusão de temáticas relacionadas à cultura africana, no currículo escolar. Em 2003, foi aprovado pelo Congresso Nacional a Lei $n^{\circ}$ 10.639/03, que normatizou o ensino obrigatório de História e Cultura Afro-Brasileira e Africana nos estabelecimentos de Ensino Fundamental e Médio, oficiais e particulares. Devido a essa lei, foram inseridos componentes curriculares com a mesma temática nos cursos de licenciaturas para capacitar os professores.

Todos esses fatos corroboraram para a formação de agenda de reivindicações por parte dos coletivos organizados (WU et al, 2014) no Estado da Bahia, para democratização de acesso à educação superior. Atenta à essas demandas, a UNEB, inicialmente, propôs à Assembleia Legislativa do Estado, como primeira iniciativa, a criação de uma lei que garantisse a reserva de $20 \%$ das vagas ofertadas para candidatos negros, em todas as Universidades Estaduais da Bahia (UEBAS) ${ }^{4}$, mas o pleito não foi atendido. Diante disso, a gestão da UNEB, utilizando-se da prerrogativa de autonomia acadêmico-administrativa, apresentou ao seu Conselho Universitário (CONSU) a proposta de criação de uma cota de $40 \%$ das vagas para candidatos pardos e negros, nos seus cursos de graduação e pós- graduação, tornando-se pioneira, no Brasil, na implementação de políticas afirmativas dessa natureza. 
Oportuno mencionarmos o respaldo legal da autonomia universitária, garantida pela Constituição Federal de 1988, que prescreve no Art. 207 "as universidades gozam de autonomia didático-científica, administrativa e de gestão financeira e patrimonial, e obedecerão ao princípio de indissociabilidade entre ensino, pesquisa e extensão". Isso só não é suficiente como afırmam Guedes e Krames (2010, p. 24). Para as autoras "é necessário que haja vontade política e compromisso com a educação". Os dados, deste estudo, revelam que a universidade vem se esforçando para corresponder a esse compromisso social e institucional.

Oficialmente, a proposta foi aprovada pelo CONSU com a Resolução n 196/2002, obtendo 28 votos a favor, 3 abstenções e nenhum contrário, o que sinaliza forte apoio dos conselheiros à decisão tomada. Após esse processo, a política de cotas da instituição passou por algumas mudanças, para ampliação do público atendido e estabelecimentos de critérios que beneficiasse mais os candidatos de baixa renda, conforme demonstrado na Figura 1, a seguir.

Como a UNEB é uma instituição que atua na vanguarda pela defesa dos direitos, à diversidade e a inclusão, em 2018 estendeu a política de cotas para outras categorias sociais, conforme estabelecido na Resolução 1.339/2018. Atitude que pode ser considerada neste momento, mais que uma audácia, mas uma transgressão aos regimes políticos e sociais vigentes no Brasil. 
Figura 1- Regulamentação da política de cotas da UNEB

\begin{tabular}{|c|c|c|}
\hline ATO NORMATIVO & VAGAS/MODALIDADE & CRITÉRIOS \\
\hline $\begin{array}{l}\text { Resolução } \\
\text { n }^{\circ} 196 / 2002\end{array}$ & $\begin{array}{l}40 \% \text { das vagas para candidatos } \\
\text { pardos e negros. }\end{array}$ & $\begin{array}{l}\text { Instituir e implementar um } \\
\text { Programa Permanente de } \\
\text { Ações Afirmativas. }\end{array}$ \\
\hline $\begin{array}{l}\text { Resolução } \\
n^{\circ} 468 / 2007\end{array}$ & $\begin{array}{l}40 \% \text { das vagas para candidatos } \\
\text { negros; } \\
5 \% \text { das vagas. }\end{array}$ & $\begin{array}{l}\text { - Obrigatoriedade: ensino } \\
\text { médio todo em escola pública; } \\
\text { - Renda familiar mensal } \\
\text { inferior ou igual a } 10 \text { (dez) } \\
\text { salários mínimos; } \\
\text { - Indígenas: comprovação } \\
\text { de pertencimento a uma } \\
\text { comunidade indígen } \\
\text { reconhecida. }\end{array}$ \\
\hline $\begin{array}{l}\text { Resolução } \\
n^{\circ} 710 / 2009\end{array}$ & & $\begin{array}{l}\text { - Todo o } 2^{\circ} \text { Ciclo do Ensino } \\
\text { Fundamental e o Ensino } \\
\text { Médio em Escola Pública; } \\
\text { - Renda bruta familiar } \\
\text { nmensal inferior ou igual a } 04 \\
\text { (quatro) salários mínimos. }\end{array}$ \\
\hline 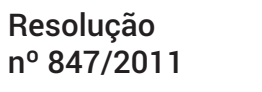 & $\begin{array}{l}5 \% \text { de sobrevagas para } \\
\text { candidatos(as) indígenas. }\end{array}$ & $\begin{array}{l}\text { Exclusivamente para os } \\
\text { cursos de graduação. }\end{array}$ \\
\hline $\begin{array}{l}\text { Resolução } \\
n^{\circ} 1.339 / 2018\end{array}$ & $\begin{array}{l}\text { I - } 40 \% \text { para candidatos(as) } \\
\text { negros(as); } \\
\text { II - } 5 \% \text { de sobrevaga para } \\
\text { candidatos(as) indígenas; } \\
\text { III - } 5 \% \text { de sobrevaga para } \\
\text { candidatos(as) quilombolas; } \\
\text { IV - } 5 \% \text { de sobrevaga para } \\
\text { candidatos(as) ciganos(as); } \\
\text { V - } 5 \% \text { de sobrevaga para } \\
\text { candidatos(as) com deficiência, } \\
\text { transtorno do espectro autista } \\
\text { ou alta habilidades; e, } \\
\text { VI - } 5 \% \text { de sobrevaga para } \\
\text { candidatos(as) transexuais, } \\
\text { travestis ou transgêneros. }\end{array}$ & $\begin{array}{l}\text { - Não possuir título de } \\
\text { graduação, exceto para } \\
\text { ingresso no processo seletivo } \\
\text { de pós-graduação. }\end{array}$ \\
\hline
\end{tabular}

Fonte: CONSU, UNEB, 2019 
A implementação da proposta teve início no final de 2002, com a oferta de vagas para o processo seletivo de 2003, em todos os cursos de graduação, computando 64.955 candidatos inscritos. Desse total, $19.863(30,57 \%)$ optaram pelo sistema de cotas, e 45.092 $(69,43 \%)$ concorreram ao restante das vagas. A demanda pelas cotas ficou aquém do que se esperava, considerando a proporção populacional de negros e pardos na Bahia. Com a maior divulgação dessa política, nos anos seguintes, aumentou-se a quantidade de inscritos e aprovados por essa política.

Importante se registrar que, com o ingresso dos cotistas o público universitário da UNEB ficou mais heterogêneo, principalmente, nos cursos de maior status, como pode ser observado na Tabela 1, que demonstra a quantidade de matriculados em 2018, por área de conhecimento. Entrentanto, cabe destacar, que as vagas dos cursos mais demandados estão sendo ocupadadas por estudantes afrodescentes e indígenas, oriundos dos melhores colégios públicos da rede estadual e federal do Brasil. Nessa perspectiva, acreditamos que a democratização de oportunidades para acesso à educação superior só será efetivada com a melhora da qualidade da Educação Básica, para que todos candidatos tenham condições de escolher e as vagas, também nos cursos mais reconhecidos social e economicamente.

Tabela 1 - Matriculados em cursos de graduação presencial de oferta regular por grande área de conhecimento CNPq e opção por cota (2018)

\begin{tabular}{|l|c|c|c|c|}
\hline $\begin{array}{l}\text { Grande área de } \\
\text { concentração de } \\
\text { conhecimento CNPq }\end{array}$ & $\begin{array}{c}\text { Cota para } \\
\text { indios }\end{array}$ & $\begin{array}{c}\text { Cota para } \\
\text { negros }\end{array}$ & Não cotistas & Total geral \\
\hline Ciências Agrárias & 35 & 430 & 717 & 1.182 \\
\hline Ciências Biológicas & 11 & 318 & 568 & 897 \\
\hline Ciências da Saúde & 48 & 1.080 & 1.448 & 2.576 \\
\hline $\begin{array}{l}\text { Ciências Exatas e da } \\
\text { Terra }\end{array}$ & 8 & 500 & 948 & 1.456 \\
\hline
\end{tabular}




\begin{tabular}{|l|c|c|c|c|}
\hline Ciências Humanas & 36 & 2.688 & 4.353 & 7.077 \\
\hline $\begin{array}{l}\text { Ciências Sociais } \\
\text { Aplicadas }\end{array}$ & 68 & 2.637 & 4.276 & 6.981 \\
\hline Engenharias & 6 & 210 & 356 & 572 \\
\hline $\begin{array}{l}\text { Linguística, Letras e } \\
\text { Artes }\end{array}$ & 5 & 1.175 & 2.045 & 3.225 \\
\hline Total & 217 & 9.038 & 14.711 & 23.966 \\
\hline
\end{tabular}

Fonte: Anuário da UNEB, 2019

Com o ingresso dos cotistas na universidade uma nova realidade foi criada, apresentando demandas estrutruais, acadêmicas e administrativas para a insituição. Pois, como se sabe, não basta só possibilitar o acesso é preciso criar possibilidades de permanência dos estudantes nos cursos, reconhecimeto social e visibilização dos mesmos no espaço acadêmico. Como estava previsto na Resolução n 196/2002, a UNEB vem criando instrumentos (Tabela 2) para implementação do Programa Permanente de Ações Afirmativas, alguns já contemplam até o público inserido na polítca de cotas, por meio da Resolução n 1.339/2018.

Tabela 2 - Ações desenvolvidas - Programa Permanente de Ações Afirmativas

\begin{tabular}{|l|l|}
\hline ANO & PROGRAMA/AÇÃO \\
\hline 2003 & $\begin{array}{l}\text { Núcleo de Estudos de Gênero e Sexualidade - NUGSEX/DIADORIM (passou a } \\
\text { ser Centro em 2015) }\end{array}$ \\
\hline 2007 & Centro de Estudos dos Povos Afro-Índios-Americanos - CEPAIA \\
\hline 2009 & $\begin{array}{l}\text { Licenciatura Intercultural em Educação Escolar Indígena - LICEEI (Prog. Esp. } \\
2018)\end{array}$ \\
\hline 2010 & $\begin{array}{l}\text { Curso de Extensão/Aperfeiçoamento em Gestão de Políticas Públicas com } \\
\text { Foco na Temática de Gênero e Raça }\end{array}$ \\
\hline 2011 & $\begin{array}{l}\text { Núcleo de Estudos Africanos e Afro-brasileiros em Línguas e Cultura - } \\
\text { NGEALC }\end{array}$ \\
\hline 2013 & Especialização em Estudos Africanos e Representações da África no Brasil \\
\hline 2013 & $\begin{array}{l}\text { Centro de Pesquisas em Etnicidades, Movimentos Sociais e Educação - } \\
\text { OPARÁ }\end{array}$ \\
\hline
\end{tabular}




\begin{tabular}{|c|c|}
\hline 2014 & Pró-Reitora de Ações Afirmativas (PROAF) \\
\hline 2014 & Licenciatura Intercultural em Educação Escolar Indígena \\
\hline 2014 & $\begin{array}{l}\text { Licenciatura em Pedagogia Intercultural em Educação Escolar Indígena } \\
\text { (DEDC-VIII/DEDC-X) }\end{array}$ \\
\hline 2014 & Revista África(s) \\
\hline 2014 & Resolução-Nº 1.094/2014 - Reconhecimento do nome social \\
\hline 2015 & Revista Série Ações Afirmativas \\
\hline 2015 & $\begin{array}{l}\text { Especialização em Gênero, Raça, Etnia e Sexualidades na Formação de } \\
\text { Educadores (Salvador) }\end{array}$ \\
\hline 2015 & Programa Afirmativo \\
\hline 2016 & I Conferência de Cotistas da UNEB - CONFCOTAS \\
\hline 2017 & Núcleo de Indígenas da UNEB - NIU \\
\hline 2017 & $\begin{array}{l}\text { Centro de Estudos e Pesquisas Intercultural e da Temática Indígena - } \\
\text { CEPITI }\end{array}$ \\
\hline 2017 & $\begin{array}{l}\text { Mestrado em Estudos Africanos, Povos Indígenas e Culturas Negras } \\
\text { PPGEAFIN }\end{array}$ \\
\hline 2017 & Coletivo de Estudantes Cotistas da UNEB - CECUN \\
\hline 2017 & Revista Coletivo SECONBA \\
\hline 2019 & Especialização em Gestão e Educação Intercultural Indígena (Paulo Afonso) \\
\hline 2019 & II Conferência de Cotistas da UNEB - CONFCOTAS \\
\hline 2019 & Coletivo de Estudante Ciganos(as) da UNEB - Tendeiros \\
\hline 2019 & $\begin{array}{l}\text { União de Estudantes Transgêneros, Transsexuais, Travesti e Não-Binárias - } \\
\text { UNETRANS+ }\end{array}$ \\
\hline 2019 & Prioridade de acesso a residência estudantil e as bolsas de permanência \\
\hline
\end{tabular}

Fonte: CONSU, UNEB, 2019

Como o sistema de cotas contempla a reserva de vagas nos cursos de pós-graduação, estima-se avanços na garantia da formação continuada dos egressos, a partir da criação de cursos de especialização e mestrado, na área de relações étnico-raciais, mas também com a ampliação de oferta de outros cursos Stricto Sensu, em áreas diversas. O total de programas de mestrados e doutorados criados pela UNEB, nas últimas décadas, passou de 3 cursos de mestrado em 2006, para 
22 programas de mestrado e 05 de doutorados em 2019, conferindo mais oportunidades de avanço na vida acadêmica.

Tabela 3 - Matriculados em cursos de pós-graduação stricto sensu por faixa etária e cor da pele autodeclarada (2018)

\begin{tabular}{|c|c|c|c|c|c|c|c|}
\hline $\begin{array}{c}\text { Faixa } \\
\text { etária }\end{array}$ & Amarela & Branca & Indígena & $\begin{array}{c}\text { Não } \\
\text { declarado }\end{array}$ & Parda & Preta & $\begin{array}{c}\text { Total } \\
\text { Geral }\end{array}$ \\
\hline $20-29$ & 5 & 21 & 3 & 63 & 48 & 67 & 207 \\
\hline $30-39$ & 5 & 33 & 1 & 154 & 118 & 120 & 431 \\
\hline $40-49$ & 1 & 41 & 2 & 115 & 93 & 59 & 311 \\
\hline $50-59$ & 1 & 23 & 1 & 33 & 43 & 20 & 121 \\
\hline $60-69$ & 0 & 3 & 0 & 5 & 5 & 6 & 19 \\
\hline $70+$ & 0 & 0 & 0 & 1 & 0 & 0 & 1 \\
\hline Total & 12 & 121 & 7 & 371 & 307 & 272 & 1.090 \\
\hline
\end{tabular}

Fonte: Anuário, UNEB, 2019

Com maior qualifıcação acadêmica, aumentam-se as oportunidades de acesso dos indígenas e afrodescendentes ao mercado de trabalho, ocupação de cargos de gestão no âmbito público e privado, ampliação de produções acadêmicas sobre minorias e melhoria das condições de vida dos segmentos beneficiados com as cotas.

O pioneirismo da UNEB com a criação de política de ações afirmativas no âmbito institucional teve repercussão nacional. Em 2003, a Universidade Estadual do Rio de Janeiro (UERJ) instituiu a reserva de $40 \%$ das vagas para alunos egressos de escolas públicas, e a Universidade de Brasília (UNB), tornou-se a primeira universidade federal a instituir cotas para negros em 2004. Essas experiências foram decisivas para a criação de políticas de ações afırmativas, para o ingresso no ensino superior, em várias instituições do Brasil, e na aprovação da Lei $n^{\circ} 12.711 / 2012$, que, incialmente, garantiu a reserva de $50 \%$ das vagas em 59 universidades federais e 38 institutos federais de educação a alunos egressos do ensino médio, na rede pública e com um recorte racial a ser definido pelas instituições, conforme critérios pré-estabelecidos na lei. 
Conforme dados da Pesquisa Nacional por Amostra de Domicílios (PNAD) em 2018, o percentual de pretos e pardos matriculados entre 2012 e 2017 aumentou, respectivamente, em 52,1\% e 37,7\%. Todavia, na UNEB, o percentual de matriculados tem diminuído nos últimos anos, em 2014, 2016 e 2018 foram, respectivamente, 40,7\%, 40,3\% e 37,7\% (Tabela 4). Panorama que merece ser mais bem pesquisado, para se identificar os motivos dessa redução.

Tabela 4 - Cotistas Matriculados na UNEB (2014 -2018)

\begin{tabular}{|l|c|c|c|c|c|}
\hline Opção por cota & 2014 & 2015 & 2016 & 2017 & 2018 \\
\hline Não cotista & 12.471 & 12.762 & 12.438 & 13.887 & 14.711 \\
\hline Cotista negro & 8.771 & 8.903 & 8.570 & 9.459 & 9.038 \\
\hline Cotista indígena & 269 & 234 & 216 & 218 & 217 \\
\hline Total & 21.511 & 21.889 & 21.224 & 23.564 & 23.966 \\
\hline
\end{tabular}

Fonte: Anuário, UNEB, 2019

Cabe destacar a necessidade de avaliação constante das ações implementadas, pois a avaliação demonstra o grau em que uma política pública está atingindo os seus objetivos e, se não estiver, o que pode ser feito para melhorá-la (WU et al, 2014). A avaliação funciona como termômetro para medir a eficiência e a eficácia das políticas, além de ter um caráter desvelador, mostrando ao público as fragilidades e limitações da própria instituição. No entendimento de lanonne (1999, p. 74), o caráter desvelador provoca uma ressonância que "perdura durante um grande espaço de tempo, oportunizando intervenções apropriadas, necessárias e subsequentes". A UNEB tem realizado a avaliação, com maior evidência, nas Conferências de Cotistas - CONFICOTAS, com a participação dos operadores e beneficiários desse sistema.

Para além de avaliar os motivos da redução de cotistas matriculados, a UNEB tem outros desafios a enfrentar, para proporcionar meIhores condições de ensino e aprendizagem aos ingressantes por cotas, em suas diversas modalidades, os quais foram explicitados pelos próprios beneficiários nas duas Conferências de Cotistas promovidas pela universidade, em 2016 e 2019 (Tabela 5). 
Tabela 5 - Desafios para consolidação da política de cotas da UNEB

DEMANDAS SINALIZADAS PELOS COTISTAS NA I E II CONFICOTAS

Implantação de polos da PROAF nos campi, para prestar apoio biopsicossocial e psicopedagógico

Programa de Bolsa permanência específica para os(as) cotistas de todas as modalidades

Criação de núcleos de apoio as pessoas com deficiência nos campi

Criação de metas e/ou cronograma para iniciar a inserção de estudantes cotistas egressos no mercado de trabalho

Concurso público para profissionais que prestem serviços específicos às pessoas com deficiência, pessoas com transtorno do espectro autista e altas habilidades.

Definição de orçamento permanente e próprio para a PROAF

Melhorar a estrutura física da UNEB para acessibilidade

Ampliação de bolsas: considerando que a população cotista representa mais de $40 \%$ do total de estudantes da UNEB

Mudanças nos currículos dos cursos de graduação para inclusão de temáticas relacionadas a História e Cultura Afro-Brasileira e indígena, Gênero e Sexualidade, Cultura Cigana, Cultura Quilombola

Seleção e Concurso público para professores(as) especializados(as) em disciplinas voltadas para temáticas de África, Afro-Brasileira, Indígena e Gênero

Formação para os servidores e docentes relacionadas as demandas das novas categorias de ingressante

Efetivação da Resolução n 1094/2014, que garante o uso do nome social a transsexuais, travestis e transgêneros, no ato da matrícula, seguido da garantia da utilização deste durante toda trajetória acadêmica;

Aperfeiçoamento do processo de validação fenótipa para cotista implantado em 2019

Fonte: Relatório da I e II CONFICOTAS, UNEB, 2019

De acordo com as análises de pesquisas publicadas, com a implementação da política de cotas para acesso à educação superior, a UNEB tem conseguido diversificar de forma crescente o público de discentes, mas o perfil do quadro de docente tem continuado praticamente inalterado, não há registro de docentes com deficiências e o quantitativo de professores indígenas em 2018 foi de 0,5\% e o de negros 15,9\%.

Outros problemas apontados pelas pesquisas revelam a necessidade de maior publicidade das informações e relatórios avaliativos do sistema de cotas, capacitação dos operadores da política nos campis, além de maior articulação e colaboração entre as pró-reitorias. 
Para conhecimento, a instituição tem quatro pró-reitorias que atendem diretamente na implementação dessa política, a saber: Pró- Reitoria de Ensino e Graduação (PROGRAD) para acompanhamento e desempenho acadêmico dos cotistas; Pró-Reitoria de Assistência Estudantil (PRAES) assegura assistência estudantil, atendimento psicológico e psicopedagógico; Pró-Reitoria de Gestão e Desenvolvimentos de Pessoas (PGDP) fomenta a formação dos técnicos e docentes; e a Pró-Reitoria de Pesquisa e Ensino de Pós-Graduação (PPG) responsável pelo incentivo à pesquisa, extensão e produção acadêmica

Alguns autores têm sinalizado os desafios dessa caminhada. SILVA (2010), destaca como obstáculos para consolidação dessa política: a insuficiência de material de pesquisa sobre a temática étnico-raciais nas bibliotecas da instituição; a manutenção de currículos etnocêntricos nos cursos de graduação e pós-graduação; e a falta de oportunidades para discussão dessas temáticas em sala de aula, as quais ainda dependem, quase que exclusivamente, da convicção ou da boa vontade do professor. Por outro lado, o autor aponta como avanços: a articulação de uma nova e ativa militância negra na UNEB; o desenvolvimento de trabalhos sociais com populações negras urbanas e rurais em Salvador e no interior do estado, e maior participação na vida política acadêmica.

Como o acesso à educação superior ainda não se encontra democratizada de forma plena, para os segmentos mais excluídos socioeconomicamente, não é possível pensar em extinção da política de cotas da UNEB, mas em fortalecimento e inclusão de outras minorias ainda excluídas.

\section{Considerações finais}

Ser otimista frente às possibilidades das políticas públicas, de modo particular, às educacionais, requer dos gestores capacidade para diagnosticar e compreender as causas e condições sociais, culturais, políticas, etc., que tornam mais complexas o cotidiano dos estudantes, principalmente, os que pertencem a um estrato social economicamente 
menos favorecido. Daí a importância das instituições, organizações sociais e todos os atores envolvidos trabalharem para intervir nas questões pertinentes ao nível local, nacional e, consequentemente, mundial, pois, as ações exitosas contribuem, sobremaneira, globalmente.

Com esse comprometimento, a UNEB, aproveitando da sua capacidade audaciosa em ser a maior instituição multicampi do Brasil, a primeira em interiorizar a educação superior no estado da Bahia, ter forte inserção social nas regiões mais esquecidas, e engajamento político-educacional, se propôs a enfrentar mais um desafio ao criar a política de cotas para democratização de acesso dos afrodescendentes à graduação e pós-graduação, tornando-se pioneira na implementação de ações afırmativas dessa natureza e amplitude, no Brasil.

O que era considerada uma política institucional teve ressonância nacional e contribuiu para mudar o público universitário, transformar vidas, desmitificar a democracia racial, empoderar sujeitos e movimentos sociais, raciais e étnicos. Apesar da efetividade dessa política, que está em processo de consolidação, a instituição também depara com diversos desafios, entre eles: assistência estudantil aos cotistas, descolonização do currículo dos cursos de graduação e pós-graduação e insuficiência de recursos orçamentários.

Assegurar e aperfeiçoar a política de cotas implementada deve ser um processo permanente da instituição, aberto à avaliação, que exige a participação de todos os atores sociais, com comprometimento no futuro, trabalho diuturno, para continuar garantindo-a. É certo que a nova conjuntura política, econômica e educacional, porque passa o país, está a exigir um engajamento maior de toda a sociedade civil, das instituições sociais e dos próprios beneficiários das políticas públicas. Com esta percepção, mais evidente fica a necessidade desse engajamento, para que o Estado mínimo não venha inviabilizar conquistas tão importantes.

Enfim, este estudo permitiu não só analisar as contribuições da política de cotas para democratização de acesso à educação superior criada pela UNEB, a ressonância dessa política no contributo com as políticas 
nacionais, assim como, identificar as diversas ações implementadas por essa instituição, com vistas a assegurar o direito à educação na perspectiva da diversidade e da inclusão. Afınal, como instituição social que o é, a universidade tem a finalidade de contribuir com a dignidade humana, com bases sociais mais justas e igualitárias (DIAS SOBRINHO, 2016). Abriga-se, fortemente, a esperança nessa instituição.

\section{Referências}

AGÊNCIA INOVAÇÃO. UNEB integra ranking das melhores universidades da América Latina. Disponível em https://www.inovacao.uneb.br/index.php/ uneb-integra-ranking-das-melhores-universidades-da-america-latina/. Acesso em 11 de agosto de 2020.

BOAVENTURA, Edivaldo Machado. A construção da universidade baiana: origens, missões e afrodescendência. Salvador: EDUFBA, 2009.

BRASIL. Constituição da República Federativa do Brasil (1988). Disponível em http://www.planalto.gov.br/ccivil_03/constituicao/constituicao.htm. Acesso em 10 de agosto de 2020.

CHAUI, Marilena. A universidade pública sob nova perspectiva. Revista Brasileira de Educação, n. 24, p. 5-15, set/out/nov/dez. 2003.

CONSU - Conselho Universitário. Resoluções no 196/2002; 468/2007; 847/2011; 1.339/2018. Disponível em: https://portal.uneb.br/conselhos/atos-administrativos-consu/. Acesso em 08 de agosto de 2020.

DIAS SOBRINHO, José. Autonomia, formação e responsabilidade social: fınalidades essenciais da universidade. Revista FORGES, v. 4, n. 2, p. 13-30, 2016.

DIAS SOBRINHO, José. Dilemas da educação superior no mundo globalizado: sociedade do conhecimento ou economia do conhecimento? São Paulo: Casa do Psicólogo, 2005.

FRASER, Nancy. Mapeando a imaginação feminista: da redistribuição ao reconhecimento e à representação. Revista Estudos Feministas, v. 15, n. 2, p. 291-308, maio-agosto, 2007.

GUEDES, Marilde Queiroz; KRAMES, Ilisabet Pradi. O processo de avaliação interna desenvolvido nas instituições para atender aos SINAES. In: LARA, Marcos Rodrigues; MONIZ, Maria Isabel A. Souza; ABRAMOWICZ, Mere (Orgs.). Políticas públicas de avaliação: uma pesquisa em currículo. Curitiba: CRV, 2010. p. 19-31. 
IANNONE, Leila Rentroia. Avaliação institucional: relato de uma experiência. In: CAPPELLETTI, Isabel Franchi (Org.). Avaliação educacional: fundamentos e práticas. São Paulo: Editora Articulação Universidade/Escola, 1999. p. 5-18.

IBGE - Instituto Brasileiro de Geografia e Estatística. Pesquisa Nacional por Amostra de Domicilios (PNAD) 2000. Disponivel em: https://biblioteca.ibge. gov.br/visualizacao/livros/liv98887.pdf. Acesso em 15 agosto de 2020.

IPEA - Instituto de Pesquisa Econômica Aplicada. Produto Interno Bruto (PIB). Disponivel em: https://economia.estadao.com.br/noticias/geral,anos-2010-foram-os-piores-para-pib-no-pais,70003155410. Acesso em 10 de ago. 2020.

OLIVEIRA, Adão Francisco de. Políticas públicas educacionais: conceito e contextualização numa perspectiva didática. In. OLIVEIRA, Adão Francisco de; PIZZIO, Alex; FRANÇA, George. Fronteiras da Educação: desigualdades, tecnologias e políticas. Goiás: PUC Goiás, 2010. p. 93-99.

ONU - Organização das Nações Unidas. Relatório de desenvolvimento humano do PNUD destaca altos índices de desigualdade no Brasil. Disponível em: https://nacoesunidas.org/relatorio-de-desenvolvimento-humano-do-pnud-destaca-altos-indices-de-desigualdade-no-brasil/. Acesso em 15 de agosto de 2020 .

SANTOS, Júlio Teles dos. Dilemas atuais das políticas para os afro-brasileiros: ação afırmativa no Brasil dos anos 60". In: BACELAR, Jeferson; CAROSO, Carlos (org). Brasil: um país de negros? Rio de Janeiro: Pallas. 1999. p. 209-212.

SILVA, Valdélio Santos Políticas de ações afırmativas na UNEB: memórias de um acontecimento histórico. Mujimbo v. 1, n. 1, julho, 2010.

SOUZA, Celina. Coordenação de políticas públicas. Brasília: ENAP, 2018.

UNEB - Universidade do Estado da Bahia. Anuário UNEB em dados 2019: base 2018. Salvador-BA: UNEB, 2019. Disponivel em https://portal.uneb.br/ seavi/wp-content/uploads/sites/134/2019/12/ANUARIO_2019_BASE_2018. pdf. Acesso em 13 julho de 2020.

UNEB - Universidade do Estado da Bahia. I Conferência de estudantes cotistas da UNEB: relatório final. Salvador: UNEB, 2016. Disponível em https:// portal.uneb.br/proaf/wp-content/uploads/sites/65/2019/09/Relatorio-CONFCOTAS-Completo_compressed.pdf. Acesso em 16 de jul., 2020. 
UNEB - Universidade do Estado da Bahia. /l Conferência de estudantes cotistas da UNEB: relatório final. Salvador: UNEB, 2019. Disponível em www: url:https://portal.uneb.br/proaf/wp-content/uploads/sites/65/2019/12/Relat\%C3\%B3rio-Final-II-ConfCotas.pdf. Acesso em 16 de julho de 2020.

WU, Xun; RAMESSH, Michael; HOWLETT, Michael; FRITZEN, Scott. Guia de políticas públicas: gerenciando processos. Traduzido por Ricardo Avelar de Souza. Brasília: ENAP, 2014.

\section{Notas}

1 Mestranda do Programa de Ciências Humanas e Sociais (UFOB). Especialista em Coordenação Pedagógica (UCAN). Analista Universitária - Pedagoga da Universidade do Estado da Bahia (UNEB-Campus IX. Brasil. ORCID-ID: https://orcid. org/0000-0001-9192-0037.E-mail: apanjos@uneb.br.

2 Pós-Doutorado (Universidade de Lisboa). Doutorado em Educação: Currículo (PUC-SP). Professora da Universidade do Estado da Bahia (UNEB-Campus IX e do Programa de Pós-Graduação em Ciências Sociais e Humanas (UFOB). ORCID-ID: https://orcid.org/0000-0002-9722-7505. E-mail: mguedes@uneb.br.

316 anos da política de cotas na UNEB: o que os dados acadêmicos revelam? (Projeto de pesquisa, DCH-Campus IX, 2018-atual), Política de cotas: institucionalização democrática de acesso à universidade para combater a desigualdade social (resumo expandido em anais do I Seminário de Ciências Humanas e Sociais UFOB, 2018); Os desafios da política de cotas na educação superior brasileira no século XXI (capítulo de livro publicado pela POISSON, 2019); Interculturalidade e políticas de ações afirmativas étnico-raciais: desafios e perspectivas dos currículos dos cursos de formação de professores (Projeto de pesquisa do mestrado, UFOB, 2019).

4 Universidade do Estado da Bahia (UNEB), Universidade Estadual de Feira de Santana (UEFS), Universidade Estadual de Santa Cruz (UESC) e Universidade Estadual do Sudoeste da Bahia (UESB). 